Portland State University

PDXScholar

$11-18-1987$

\title{
The Differential Role of the SSI with Normal Preschool Children
}

Caroline Joy Semler

Portland State University

Follow this and additional works at: https://pdxscholar.library.pdx.edu/open_access_etds

Part of the Speech Pathology and Audiology Commons Let us know how access to this document benefits you.

\section{Recommended Citation}

Semler, Caroline Joy, "The Differential Role of the SSI with Normal Preschool Children" (1987).

Dissertations and Theses. Paper 3732.

https://doi.org/10.15760/etd.5616

This Thesis is brought to you for free and open access. It has been accepted for inclusion in Dissertations and Theses by an authorized administrator of PDXScholar. Please contact us if we can make this document more accessible: pdxscholar@pdx.edu. 
AN ABSTRACT OF THE THESIS OF Caroline Joy Semler for the Master of Science in Speech Communication presented November $18,1987$.

Title: The Differential Role of the SSI with Normal Preschool Children.

APPROVED BY MEMBERS OF THE THESIS COMMITTEE:
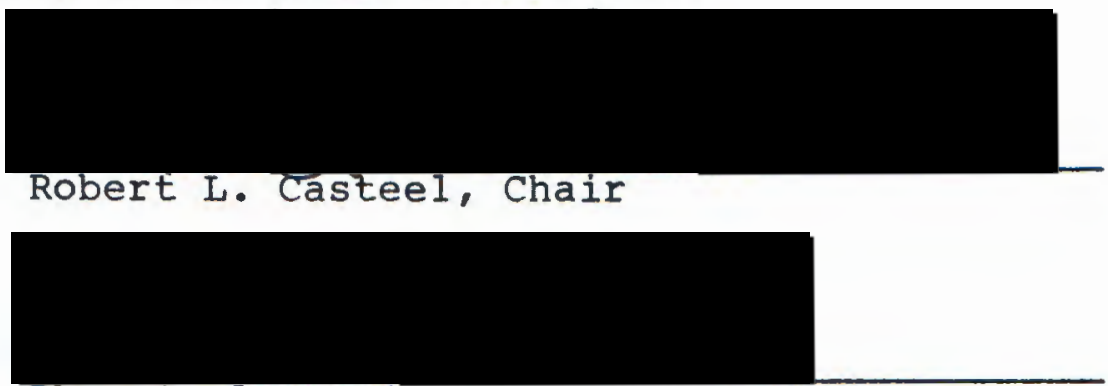

Rhea paul

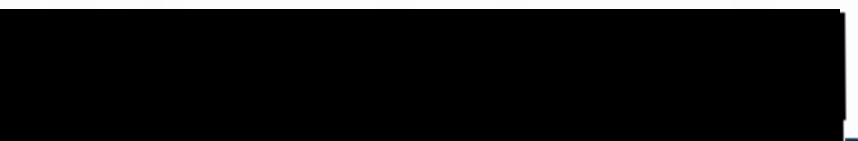

Carol Tama

The onset of stuttering usually occurs between two and six years which is the same time most children exhibit normal disfluencies often making it difficult to differentiate between normally disfluent children and incipient stutterers (DeJoy \& Gregory, 1985). Clinicians need information on the types and frequencies of disfluencies exhibited by normal preschool children in order to determine if a child is more likely to be an incipient stutterer or normally disfluent child. Some clinicians feel 
uncomfortable relying on past literature since there is a limited amount of information available and the studies have shown a considerable amount of variability in the types and frequencies of disfluencies demonstrated by children.

The SSI is an instrument that purports to determine the severity of stuttering, however, with preschool children it does not distinguish at its lower levels the normally disfluent child from the beginning stutterer. The chief problem with the instrument is that all children are labeled stutterers. In addition, no data on normal preschool children has been published.

The purpose of this study was to investigate the disfluency characteristics of normal 33-39 month old children in order to determine the differential role of the SSI with young children. The following questions were answered :

1. What are the types and frequencies of disfluencies demonstrated by normal 33-39 month old children?

2. How do the scores of normal 33-39 month old children distribute on the stuttering severity Instrument?

Twenty 33-39 month old normal children participated in the study. Means and standard deviations for the types of disfluencies and SSI scores were calculated for each child. The types and frequencies of disfluencies demonstrated tend to support past literature with whole-word repetitions, 
revision-incomplete phrases and interjections occurring the most frequently.
All of the children scored as very mild or mild stutterers on the SSI. The normal repetitions that caused children to score as stutterers were primarily whole-word repetitions of one syllable and part-word repetitions. None of the normally disfluent children demonstrated physical concomitants or durations longer than a fleeting moment. This appears to indicate treatment should be considered for children scoring above mild on the SSI or demonstrating dysrhythmic phonations, tense pauses, physical concomitants and druations longer than a fleeting moment. 
THE DIFFERENTIAL ROLE OF THE SSI

WITH NORMAL PRESCHOOL CHILDREN

by

CAROLINE JOY SEMLER

A thesis submitted in partial fulfillment of the requirements for the degree of

\author{
MASTER OF SCIENCE \\ in \\ SPEECH COMMUNICATION : \\ with emphasis in \\ SPEECH-LANGUAGE PATHOLOGY
}

Portland State University

1987 
TO THE OFFICE OF GRADUATE STUDIES AND RESEARCH:

The members of the Committee approve the thesis of Caroline Joy Semlef-Rresented November 18, 1987.

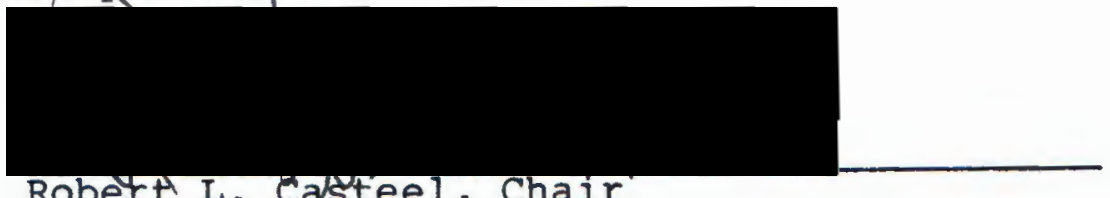

Robert I. Casteel, Chair

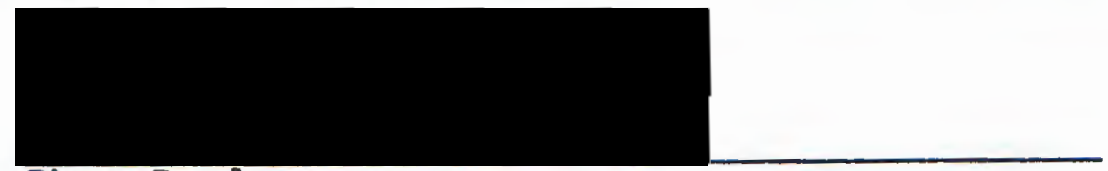

Rhea Paul

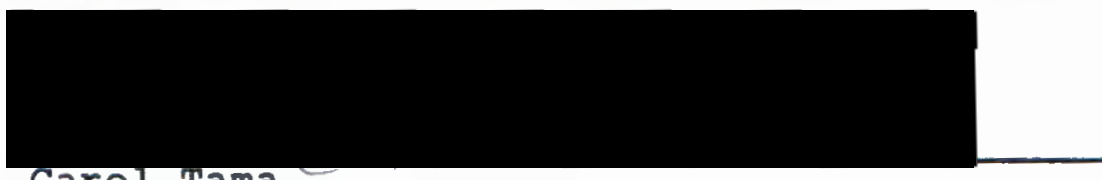

Carol Tama

APPROVED:

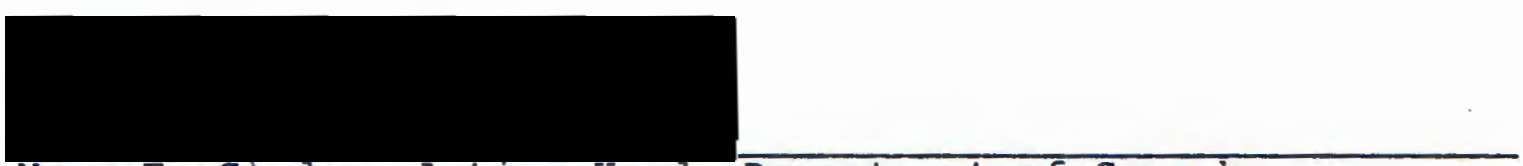

Mary E. Gardon, Acting Head, Department of Speech

Communication

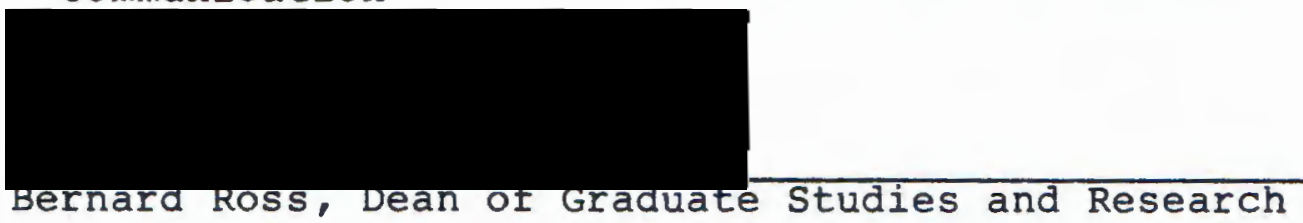




\section{ACKNOWLEDGEMENTS}

I would like to thank all the people who provided me with the guidance and support I needed to see the project through.

A sincere thank you to:

The parents and children who participated in this study:

The members of my thesis committee: Robert L. Casteel, Rhea Paul, and Carol Tama;

My family, boyfriend and closest friends. 


\section{DEDICATION}

I would like to dedicate this to my family who provided me with the constant love and support I needed to see this project through. Thanks for always being there for me. I would have never made it if it wasn't for such a loving, caring family. 
TABLE OF CONTENTS

PAGE

ACKNOWLEDGEMENTS

LIST OF TABLES

CHAPTER

I INTRODUCTION AND STATEMENT OF PURPOSE • • • 1 INTRODUCTION • • • . . . . . . . . . . 1

Statement of purpose . . . . . . . . 2

Definition of Terms . . . . . . . . 3

I I REVIEW OF THE LITERATURE • . . . . . . . 6

Characteristics of Normally

Disfluent Children . . . . . . 6

Characteristics of Incipient

Stutterers ........... . 14

Early Identification . . . . . . . 16

Differential Diagnosis . . . . . . 18

III METHODS . . . . . . . . . . . 23

Subjects . . . . . . . . . . . 23

Subject Eligibility Procedures . . . . . 24

Speech Sample Procedures . . . . . . 25

Scoring Procedures . . . . . . . . 25

Reliability . • . • . . . . . . 26

Date Analysis . . . . . . . . . 27 
IV RESULTS AND DISCUSSION - • • • • • • • • Results . . . . . . . . . . . . 28 Discussion . . . . . . . . . . . 30

V SUMMARY AND IMPLICATIONS • • • • • • • • • 37

Summary • • • • • • • . . . • . 37

Clinical Implications . . . . . . 38

Research Implications . . . . . . . 40

BIBLIOGRAPHY • • • • • • • • • • • • • • • • • 44 APPENDIX
A PARENT LETTERS • . . . . . . . . . . . 43
B CONSENT FORM . . . . . . . . . . . . . . 44
C LIST OF StIMULI - • • • • • • • • • • • • 45
D DISFLUENCY RECORD - • • • • • • • • • • . 46

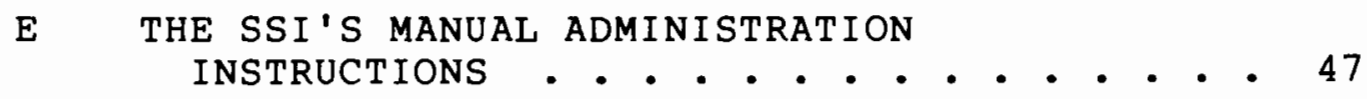
F INSTRUCTIONS FOR SELECTION OF CONTENT
TRANSCRIPTS FOR RELIABILITY TESTING $\quad \bullet \quad \cdot \quad 50$
G INSTRUCTIONS FOR RELIABILITY JUDGES • • • • 53 


\section{LIST OF TABLES}

TABLE

PAGE

I Means of Specific Types of Disfluencies

Observed in Studies by Branscom,

Hughes and Oxtoby - . . . . . . . . 8

I Means and Standard Deviations of Specific

Types of Disfluencies Observed by Yairi • 10

II Means and Standard Deviations of Types of

Disfluencies Observed by Wexler

and Mysak

IV A Comparison of Several Researchers Findings

on Normal Disfluencies . . . . . . . . 12

$\mathrm{V} \quad$ Characteristics of Incipient stutterers

and Normally Disfluent Children . . . . - 17

VI Children's Severity Conversion Table • • • • 21

VII Disfluencies Demonstrated by 33-39 Month

Old Normal Children . . . . . . . . 29

VIII SSI Scores of Normal 33-39 Month old

Children . . . . . . . . . . . . 31

IX Rank Order of Types of Disfluencies

Demonstrated by 33-39 Month old Normal

Children . . . . . . . . . . . . . 33 


\section{CHAPTER I}

INTRODUCTION AND STATEMENT OF PURPOSE

\section{INTRODUCTION}

Speech-Language Pathologists are often responsible for determining if a child is normally disfluent or has a fluency disorder. A reliable diagnosis is difficult to make because the onset of stuttering usually occurs between two and six years of age which is the same time most children exhibit normal disfluencies (DeJoy \& Gregory, 1985). Even though it is often difficult to differentiate between incipient stutterers and normally disfluent children it is important to make this differentiation in order to determine if intervention is warranted. Clinicians need information on the types and frequencies of disfluencies exhibited by normal preschool children in order to determine which children are more likely to move through the developmental stage and which are more likely to become stutterers. There is a limited amount of information on disfluencies in the literature. In addition, some clinicians feel uncomfortable relying on this information because the studies have shown a considerable amount of variability in the types and frequencies of disfluencies demonstrated by children. 
The Stuttering Severity Instrument (Riley, 1972) is an instrument that purports to determine the severity of stuttering, however, with preschool children it does not distinguish at its lower levels the normally disfluent child from the beginning stutterer. The SSI is a tool that analyzes the client's repetitions, the duration of disfluencies and accompanying physical concomitants gathered in a 100 word speech sample to determine a severity rating of stuttering behavior. The chief problem with the instrument is that all children taking the test are labeled stutterers for it is scaled for stuttering, the scores on the instrument range from 0 to 45 . In addition, no data on normal preschool children has been published. Since normal preschool children do exhibit disfluencies and are labeled as stutterers on this instrument, clinicians need to know how normal children score on the SSI in order to determine if concern is waranted. Therefore, the following study was designed.

Statement of Purpose

The purpose of this study was to investigate the disfluency characteristics of normal 33-39 month old children in order to determine the differential diagnostic value of the SSI with young children. The following questions will be answered: 
1. What are the types and frequencies of disfluencies demonstrated by normal 33-39 month old children?

2. How do the scores of normal 33-39 month old children distribute on the stuttering severity Instrument?

\section{Definition of Terms}

Broken words: Abnormal stoppage of voice or airflow within a word.

Disfluency: A disruption in the normal flow of speech which is characterized by involuntary, audible or silent, repetitions or prolongations (Van Riper, 1971; wingate, 1964).

Dysrhythmic phonation: The audible or silent continuation of a sound or articulatory posture which disturbs or distorts the normal rhythm of flow of speech (Williams, Silverman \& Kool, 1968). Dysrhythmic phonations are also referred to as prolongations and include broken words (Yairi, 1981).

Incipient stutterer: A child who is beginning to demonstrate the characteristics of a stutterer (Adams, 1977).

Interjection: A sound inserted within the flow of speech which is not part of the message (e.g., uh, er, um, well-I mean).

Intrusive schwa: The presence of the neutral schwa vowel intruding on the intended vowel (e.g., buh, buh, boat) (Van Riper, 1971).

Nonfluency: Interruption in the normal flow of speech. Also referred to as disfluency.

Normal disfluency: Interruptions in the flow of speech which are demonstrated to some degree by nearly all speakers and which do not warrant concern or intervention.

Part-word repetition: The repetition of a sound or syllable unit which is less than the entire word. For example, $s-s-s u n$ is a sound repetition and ta-ta-table is a syllable repetition. 
Phrase repetition: The unintentional repetition of two or more words. For example, and he-and he-and he drove home.

Physical concomitants: The visible and audible phenomena which accompany the stuttered speech (Riley, 1972). Riley (1972) lists four categories of physical concomitants: distracting sounds (e.g., hissing noise, throat clearing), distracting facial grimaces (e.g., eye blinks, tongue protrusion), distracting head movements (e.g., turning head from listener, looking at floor), and distracting movements of the extremities (e.g., foottapping, arm swaying).

Prolongations of sounds and syllables: The silent or audible continuation of a sound or articulatory posture beyond what is perceived as normal in length (Riley, 1972; Fraser, 1985).

Revision-incomplete phrase: Making a new version of a phrase to alter a thought, word or idea (e.g., the cat-the dog ran). Also referred to as false start.

Stuttering: "stuttering occurs when sounds or syllables are repeated, vowels are prolonged, or the air-voice stream is arrested at the laryngeal level or impeded by abnormal articulatory postures. It is aggravated by the child's reactions to the disfluencies and by attempts to avoid sounds, words, situations or audiences associated with the disfluencies" (Riley, $1981)$.

Stuttering Severity Instrument (SSI): A tool devised by Riley (1972) that analyzes a client's repetitions, duration of disfluencies and accompanying physical concomitants gathered in a 100 word speech sample to determine a severity rating of stuttering behavior.

Tense pause: A disfluency that occurs between words, partwords and nonwords when at the between point in question there are barely audible manifestations of heavy breathing or muscular tightening. The same phenomena within a word would place the word in the category of dysrhythmic phonation (williams et al, $1968)$.

Unit Repetition: Each repetition of a sound, syllable, or word prior to the production of the intended utterance is counted as one unit repetition. For example, b-bbutter is two unit repetitions and he-he-he-he will is three unit repetitions (Yairi, 1981). 
Whole word repetition: The repetition of an entire word. A single syllable word repetition consists of the repetition of a one syllable word whereas a polysyllabic whole word repetition consists of the repetition of a word with more than one syllable. For example, the-the is a single syllable word repetition and flower-flower is a polysyllabic whole word repetition. 
CHAPTER II

REVIEW OF THE LITERATURE

Characteristics of Normally

Disfluent Children

Preschool children tend to exhibit a period of normal disfluency when they are acquiring speech and language skills with no significant difference in the disfluencies demonstrated based on sex (Yairi, 1981). By the time children reach 33-39 months of age it is reasonable to expect them to use enough intelligible, connected speech and stay on task for a long enough period of time to assess their fluency. Utterance lengths ranging from 2.8 to 5.4 words are typical of three-year-old children's speech (Peterson and Marquardt, 1981). In addition they tend to be 80-90 percent intelligible (Hopper and Naremore, 1978). Even though these children are old enough to assess their fluency, a limited amount of research has been completed describing the types and frequencies of normal disfluencies demonstrated by these children but some of the research has conflicting results. In addition, the literature indicates researchers have observed so much variability in the number and types of disfluencies demonstrated by preschoolers that the standard deviations often approach or exceed the means 
of the number and types of disfluencies observed (DeJoy \& Gregory, 1985).

Branscom, Hughes, and Oxtoby (1955) wrote an article discussing the results of their theses on nonfluencies in normal children who ranged from two to five years of age. They investigated syllable, word and phrase repetitions. Oxtoby gathered speech samples through free play while Branscom and Hughes administered a speech test which consisted of a set of items used to elicit speech. They hand recorded the child's utterances as she or he spoke. Branscom, Hughes and Oxtoby report every child demonstrated some disfluencies. They came to the conclusion that repetitions are definitely a part of all young children's speech. As can be seen in Table I, Branscom and Hughes found word repetitions were the most common type of repetition while oxtoby reported phrase repetitions were the most frequently observed type of repetition. The discrepancy may be a result of the two different methods used to gather data. All three investigators agreed syllable repetitions, often referred to as part-word repetitions in more recent literature, occurred the least frequently.

Branscom, Hughes and Oxtoby (1955) came up with the following conclusions after examining their data: as children get older, the frequency of their repetitions decreases; there is little relationship between a child's 
TABLE I

MEANS OF SPECIFIC TYPES OF

DISFLUENCIES OBSERVED IN

STUDIES BY BRANSCOM,

HUGHES AND OXTOBY

\begin{tabular}{|c|c|c|c|c|c|}
\hline Investigator & $\begin{array}{c}\text { Age of } \\
\text { Subjects }\end{array}$ & SRI/100W & WRI/110W & PRI/ 100W & TRI/100W \\
\hline $\begin{array}{l}\text { Branscom } \\
\text { Median }\end{array}$ & 3 years & $\begin{array}{l}.45 \\
(.21)\end{array}$ & $\begin{array}{c}2.62 \\
(2.38)\end{array}$ & $\begin{array}{c}1.08 \\
(1.05)\end{array}$ & $\begin{array}{c}4.18 \\
(4.04)\end{array}$ \\
\hline $\begin{array}{c}\text { Branscom } \\
\text { Median }\end{array}$ & 4 years & $\begin{array}{l}.42 \\
(.29)\end{array}$ & $\begin{array}{c}2.48 \\
(1.71)\end{array}$ & $\begin{array}{l}.85 \\
(.43)\end{array}$ & $\begin{array}{c}3.73 \\
(2.45)\end{array}$ \\
\hline $\begin{array}{c}\text { Branscom } \\
\text { Median }\end{array}$ & 5 years & $\begin{array}{l}.29 \\
(.30)\end{array}$ & $\begin{array}{c}1.97 \\
(1.45)\end{array}$ & $\begin{array}{l}.92 \\
(.75)\end{array}$ & $\begin{array}{c}3.42 \\
(2.46)\end{array}$ \\
\hline $\begin{array}{l}\text { Hughes } \\
\text { Median }\end{array}$ & 2 years & $\begin{array}{l}.91 \\
(.91)\end{array}$ & $\begin{array}{c}1.81 \\
(1.74)\end{array}$ & $\begin{array}{c}1.33 \\
(1.48)\end{array}$ & $\begin{array}{c}4.06 \\
(4.28)\end{array}$ \\
\hline $\begin{array}{l}\text { Hughes } \\
\text { Median }\end{array}$ & 4 years & $\begin{array}{c}.97 \\
(.86)\end{array}$ & $\begin{array}{c}1.13 \\
(1.01)\end{array}$ & $\begin{array}{l}.56 \\
(.56)\end{array}$ & $\begin{array}{c}2.66 \\
(2.26)\end{array}$ \\
\hline $\begin{array}{l}\text { Oxtoby } \\
\text { Median }\end{array}$ & 3 years & $\begin{array}{c}1.03 \\
\mathrm{NA}\end{array}$ & $\begin{array}{c}1.48 \\
\mathrm{NA}\end{array}$ & $\begin{array}{c}2.23 \\
\text { NA }\end{array}$ & $\begin{array}{c}4.76 \\
\mathrm{NA}\end{array}$ \\
\hline
\end{tabular}

SRI/100W: Syllable Repetition Instances per 100 words

WRI/100W: Word Repetition Instances per 100 Words

PRI/100W: Phrase Repetition Instances per 100 Words

TRI/100W: The total number of repetition instances per 100 words 
frequency of repetitions and their intelligence; and there are no statistically significant differences between the number of repetitions demonstrated by boys and girls. More recent literature not only includes word, phrase and syllable repetitions but also looks at other types of disfluencies such as dysrhythmic phonations, revisionincomplete phrases, interjections and tense pauses. The development of recording techniques made it easier for more recent investigators to look at a larger number of types of disfluencies. Yairi (1981) considered eight different types of disfluencies when studying normally disfluent two year old children. Yairi categorized the speech of thirty-three 24- to 33-month-old children into the following groups: part-word repetitions, single-syllable word repetitions, polysyllabic word repetitions, phrase repetitions, interjections, revision-incomplete phrases, disrhythmic phonations, and tense pauses. As can be seen in Table II, Yairi found that part-word repetitions, single syllable word repetitions and interjections were the most frequently observed types of disfluencies. He also noted boys tended to demonstrate more part-word repetitions than girls but there was not a statistically significant difference between the two groups.

Yairi also reported the total number of disfluencies ranged from 0 to 25.6 with a mean of 6.49 . As can be seen from these figures, Yairi found much diversity among the 
TABLE I I

MEANS AND STANDARD DEVIATIONS OF SPECIFIC TYPES OF DISFLUENCIES

OBSERVED BY YAIRI

\begin{tabular}{|c|c|c|c|c|c|c|c|c|c|}
\hline & PWR & SSW & PSW & PR & INT & REV & DP & $\mathrm{TP}$ & TD \\
\hline $\begin{array}{l}\text { Boys } \\
\text { Mean }\end{array}$ & 1.53 & 1.56 & .07 & .54 & 1.95 & 1.32 & .48 & .50 & 7.95 \\
\hline S.D. & 1.33 & 1.70 & .14 & .50 & 2.26 & 1.40 & .80 & .84 & 6.39 \\
\hline $\begin{array}{l}\text { Girls } \\
\text { Mean }\end{array}$ & .96 & 1.12 & .07 & .60 & .92 & .87 & .36 & .34 & 5.24 \\
\hline S.D. & .91 & .88 & .18 & .40 & .84 & .98 & .50 & .47 & 3.35 \\
\hline $\begin{array}{l}\text { Boys \& } \\
\text { Girls } \\
\text { Mean }\end{array}$ & 1.22 & 1.32 & .07 & .57 & 1.38 & 1.07 & .43 & .43 & 6.49 \\
\hline S.D. & 1.13 & 1.30 & .16 & .44 & 1.70 & 1.18 & .69 & .74 & 5.04 \\
\hline $\begin{array}{ll}\text { PWR: } & p \\
\text { SSW: } & \text { s } \\
\text { PSW: } & p \\
\text { PR: } & p \\
\text { INT: } & i\end{array}$ & $\begin{array}{l}\text { e-syl } \\
\text { sylla } \\
\text { e rep } \\
\text { jecti }\end{array}$ & $\begin{array}{l}\text { ble wh } \\
\text { c wor } \\
\text { ition } \\
\end{array}$ & $\begin{array}{l}\mathrm{d} \text { re } \\
\text { repe }\end{array}$ & $\begin{array}{l}\text { ition } \\
\text { ion }\end{array}$ & & & $\begin{array}{l}\text { ision } \\
\text { hyth } \\
\text { se pal } \\
\text { l di }\end{array}$ & pho & ation \\
\hline
\end{tabular}


children in regards to the total frequency of disfluency with some children exhibiting ten times more disfluencies than others. He also found that the children did not form a normal distribution curve but an irregular one with the largest concentrations of subjects at the lower end of the range and in the middle of the range.

More recently, Wexler and Mysak (1982) studied the disfluencies of normal two-, four-, and six-year-olds. They examined 12 boys in each of the three age groups identifying and classifying interjections, part-word repetitions, word repetitions, phrase repetitions, revision-incomplete phrases, disrhythmic phonations and tense pauses. They also noted clustering: "the occurrence of more than one disfluency on the same word or consecutive words or both" and oscillation, "the number of repetitions per instance of disfluency" (Wexler \& Mysak, 1982).

Wexler \& Mysak's findings indicate revision-incomplete phrases and interjections are the most frequently occurring types of disfluencies amongst all three age groups. Phrase repetitions and word repetitions were the next two most frequently occurring types of repetitions for two-year-olds. Part-word repetitions and word repetitions occurred the least frequently for two- and four-year-olds. See Table III. In a comparison of past literature, although there is some overlap in the findings of several researchers there also is a great deal of variation. As can be seen in Table IV 
TABLE III

MEANS AND STANDARD DEVIATIONS OF SPECIFIC TYPES

OF DISFLUENCIES OBSERVED BY WEXLER AND MYSAK

\begin{tabular}{lllllllll}
\hline \hline & RIP & INT & PR & WR & DP & TP & PWR & TF \\
\hline $\begin{array}{l}\text { 2 Year olds } \\
\text { Mean }\end{array}$ & 3.5 & 3.0 & 2.2 & 2.1 & 1.5 & 1.5 & 0.7 & 14.6 \\
$\begin{array}{l}\text { S.D. } \\
\text { Y year olds }\end{array}$ & 2.3 & 2.0 & 1.4 & 0.9 & 1.3 & 1.3 & 0.6 & 5.7 \\
$\quad$ Mean & 2.6 & 2.6 & 0.6 & 0.9 & 0.6 & 1.5 & 0.4 & 9.1 \\
$\begin{array}{l}\text { S.D. } \\
\text { Y year olds } \\
\quad \text { Mean }\end{array}$ & 1.5 & 1.8 & 0.5 & 0.8 & 0.5 & 1.0 & 0.3 & 3.2 \\
S.D. & 2.3 & 3.4 & 0.7 & 0.9 & 0.2 & 1.1 & 0.6 & 9.1 \\
& 1.0 & 2.7 & 0.7 & 0.6 & 0.2 & 1.6 & 0.5 & 4.1
\end{tabular}

RIP: revision-incomplete phrase

INT : interjection

PR: phrase repetition

WR: word repetition
DP: dysrhythmic phonation TP: tense pause

PWR: part-word repetition TF: total frequency

TABLE IV

A COMPARISON OF SEVERAL RESEARCHERS'

FINDINGS ON NORMAL DISFLUENCIES

\begin{tabular}{lccccc}
\hline \hline & $\begin{array}{l}\text { Branscom } \\
3 \text { yr olds }\end{array}$ & $\begin{array}{c}\text { Oxtoby } \\
3 \text { yr olds }\end{array}$ & $\begin{array}{c}\text { Hughes } \\
2 \text { yr olds }\end{array}$ & $\begin{array}{c}\text { Yairi } \\
2 \text { yr olds }\end{array}$ & $\begin{array}{c}\text { Wexler \& Mysak } \\
2 \text { yr olds }\end{array}$ \\
\hline SRI/PWR & .45 & 1.03 & .91 & 1.22 & 0.7 \\
WR & 2.62 & 1.48 & 1.81 & 1.32 (SSW) & 2.1 \\
& & & -07 & (PSW) & \\
PR & 1.08 & 2.23 & 1.33 & .57 & 2.2 \\
INT & - & - & - & 1.38 & 3.0 \\
REV/RIP & - & - & - & 1.07 & 3.5 \\
DP & - & - & - & .43 & 1.5 \\
TP & - & - & - & .43 & 1.5 \\
TD & 4.18 & 4.76 & 4.06 & 6.49 & 14.6 \\
& & & & & \\
\hline
\end{tabular}

SRI : syllable repetition instance PWR: part-word repetition

WR: word repetition

PR: phrase repetition

INT: interjection

REV: revision
RIP: revision-incomplete phrase DP: phonation

TP: pause

TD: disfluency

SSW: single syllable word repetition PSW: polysyllabic word repetition 
Branscom found 3-year-olds mainly produce word repetitions while oxtoby found they mainly produce phrase repetitions. They both agree 3-year-olds produce syllable repetitions the least frequently although Oxtoby's subjects produced more syllable repetitions than Branscom's subjects.

Hughes and Yairi both found word repetitions predominate in two-year-old children's speech. Yairi also found interjections, something Hughes did not consider, play just as large of a role as whole word repetitions in twoyear-old children's speech. Wexler and Mysak discovered their two-year-old subjects mainly demonstrated revisionincomplete phrases and interjections. Hughes and Wexler and Mysak discovered part-word repetitions occurred the least frequently while Yairi reports disrhythmic phonations and tense pauses occur the least frequently. Not only did these researchers vary in the results of individual types of disfluencies but their subjects varied in overall frequency with Wexler and Mysak's subjects being more than three times as disfluent as Hughes's subjects. The studies generally agree though that the larger unit repetitions such as revision-incomplete phrases and whole-word repetitions occur more frequently in normally disfluent children's speech then the smaller unit repetitions such as part-word repetitions and dysrhythmic phonations. 
Characteristics of Incipient Stutterers

The great amount of variability in the speech behavior of preschoolers often makes it difficult to separate the characteristics of incipient stutterers and normally disfluent children making differential diagnosis difficult. Yairi \& Lewis (1984) observed disfluencies in children judged to be stutterers by their parents, the investigator, and a speech-language pathologist. Their subjects included 10 two-year-olds and 10 three-year-olds considered to be stutterers and matched with nonstuttering controls. Yairi and Lewis collected spontaneous speech samples from the children within two months of the onset of their stuttering. They then analyzed the speech samples examining part-word repetitions, single syllable word repetitions, multisyllable word repetitions, phrase repetitions, interjections, revision-incomplete phrases, dysrhythmic phonations and tense pauses.

The results of their study indicated the most frequently occurring disfluencies in stutterers are partword repetitions, dysrhythmic phonations and single-syllable repetitions in that order whereas the most frequently occurring disfluencies in the nonstutterers were interjections, part-word repetitions and revision-incomplete phrases. Although the stutterers were more disfluent than the controls on all types of disfluencies there was only a statistically significant difference between the two groups 
on part-word repetitions, dysrhythmic phonations and total frequency. The stutterers were three and one-half times more disfluent than the controls. Yairi and Lewis also found the standard deviations of each type of disfluency were so large that overlaps occurred in the frequencies of the two groups. The largest overlaps occurred in interjections and revision-incomplete phrases but there was little overlap in part-word repetitions and tense pauses indicating these may be a stronger indicator of a fluency disorder. Another finding of their study was that stutterers repeated segments of speech more times than the nonstutterers on all types of disfluencies except phrase repetitions. There was only a statistically significant difference though on part-word repetitions and singlesyllable word repetitions indicating the number of times a part-word repetition or single syllable word repetition is repeated might also be a discriminator between the incipient stutterer and normally disfluent child.

As mentioned before, it is often difficult to separate the characteristics of incipient stutterers and normally disfluent children. Some investigators, such as Adams, have studied past literature and have come up with characteristics they feel differentiate between incipient stutterers and normally disfluent children. First, incipient stutterers tend to be disfluent at least 10 percent of the time (Adams, 1984). They demonstrate at 
least two or three times more disfluencies than normally disfluent children (Yairi \& Lewis, 1984; Adams, 1984). Second, stutterers produce more sound prolongations (dysrhythmic phonations) and part-word repetitions than normally disfluent children (Adams, 1977; Riley, 1981). Third, audible effort and struggle behavior are often observed in the speech of incipient stutterers (Adams, 1984; Pindzola \& White, 1986). See Table $\mathrm{V}$ for a chart comparing characteristics of incipient stutterers and normally disfluent children.

\section{Early Identification}

It is important to further research characteristics of normally disfluent children and incipient stutterers to aid in differential diagnosis so the clinician can accurately evaluate and diagnose a child as early as possible. Pindzola and White (1986) report it is important to differentiate between incipient stutterers and normally disfluent children regardless of whether a direct or indirect approach is taken towards management. Adams (1980) makes an important point, stressing the need to discriminate between the incipient stutterer and the normally disfluent child as early as possible. He warns us that misdiagnosis may result in the withholding of necessary treatment for incipient stutterers and unnecessary treatment for normally disfluent children. Unnecessary treatment would be a waste 
TABLE V

CHARACTERISTICS OF INCIPIENT STUTTERERS AND NORMALLY DISFLUENT CHILDREN

Incipient Stutterers

Tend to exhibit 2 or more part-word unit repetitions (Curlee, 1984; Yairi \& Lewis, 1984).

Tend to be disfluent at least 108 of the time (Adams, 1984).

May exhibit audible or visible struggle behavior (Riley, 1972).

Disfluencies are are mainly part-word repetitions and sound prolongations (Riley, 1981).

The intended vowel rather than the schwa is perceived in the word being marked by a part-word repetition (Adams, 1977) .
Normally Disfluent Children

Tend to exhibit only one part word unit repetition (Yairi \& Lewis, 1984).

Tend to be disfluent less than 108 of the time (Adams, 1984).

Tend not to exhibit audible or visible struggle behavior (Riley, 1972; Adams, 1984).

Disfluencies are mainly whole word, phrase repetitions, interjections and revisions (Adams, 1984).

Tend to substitute a schwa for the intended vowel (Adams, 1977). 
of time and may make a child so aware of his disfluencies that he becomes a stutterer (Adams, 1980).

\section{Differential Diagnosis}

Some clinicians differentiate between incipient

stutterers and normally disfluent children by comparing the disfluencies exhibited by a child to the characteristics of normally disfluent children and incipient stutterers

described in the literature. This is often a difficult and unreliable method since there is little past literature on normal disfluencies, some of the literature conflict with each other and often standard deviations are so large they approach or exceed the mean (DeJoy \& Gregory, 1985). More research is needed on the frequencies and types of disfluencies exhibited by normal children to use this method confidently and reliably.

Another method many clinicians use to assist them in making a differential diagnosis is diagnostic instruments. The instruments available give clinicians information concerning the client's observable stuttering behaviors, the clients' stuttering severity and their feelings and attitudes in different situations. The methods or instruments used to obtain specific information are in the forms of self reports, scales and numerical formulas which measure specific disfluencies (Riley, 1972).

Adams (1977) presents a strategy to use when evaluating disfluent children. Adams reviewed past data and 
came up with the following differences between incipient stutterers and normally disfluent children: incipient stutterers demonstrate ten or more disfluencies per 100 words; incipient stutterers disfluencies are mainly partword repetitions and sound prolongations while normally disfluent children's disfluencies are mainly whole word and phrase repetitions, interjections and revisions; incipient stutterers tend to exhibit three or more unit repetitions; incipient stutterers tend to have difficulty starting or sustaining airflow; and incipient stutterers tend to substitute a schwa for the intended vowel.

Adams suggests collecting speech samples of 300-500 words from children and comparing the characteristics of their speech to the previously mentioned characteristics of stutterers and normally disfluent children. If a child possesses four or more characteristics of one of the groups, then they fall into that group, but if a child possesses three characteristics of one group and two from the other then Adams recommends monitoring him.

Another tool used to evaluate children is the Stuttering Severity Instrument which was devised by Riley (1972) to diagnose the severity of stuttering behavior because of his concern that self reports and scales are not objective and numerical formulas do not take into account other parameters of stuttering such as the duration of the disfluency and observable physical concomitants. 
The stuttering Severity Instrument is a diagnostic tool that not only considers frequencies, but also takes other characteristics of stuttering into account. It uses the following three parameters for describing stuttering: frequency of repetition and audible and inaudible prolongations of sounds and syllables, estimated duration of the longest blocks, and observable physical concomitants. The scores from these three sections of the instrument are added together resulting in an overall score. Severity ratings from very mild to very severe are assigned to the overall scores. As can be seen in Table VI, the severity ratings are further broken down into percentile groups within each severity group depending on the overall score. The overall score can be used not only as an assessment of severity, but also as a reference point to measure future clinical changes (Riley, 1972).

The stuttering Severity Instrument is a widely used test even though it has its limitation. The chief problem with the instrument is that all children are labeled stutterers. In addition, no data on the performance of normal preschool children on the SSI has been published so clinicians do not know how normal children's scores distribute on this instrument.

Riley devised a more recent instrument, the stuttering Prediction Instrument (SPI), which does provide normative data on a limited population of normal preschool children. 


\section{TABLE VI}

CHILDREN'S SEVERITY CONVERSION TABLE FOR NONREADERS

(Riley 1972)

\begin{tabular}{ccl}
\hline \hline Total Overall Score & Percentile & Severity \\
\hline $0-5$ & $0-4$ & very mild \\
\hline $6-8$ & $5-11$ & \\
$9-13$ & $12-23$ & mild \\
$14-15$ & $24-40$ & \\
\hline $16-19$ & $41-60$ & moderate \\
$20-23$ & $61-77$ & \\
\hline $24-27$ & $78-89$ & severe \\
$28-30$ & $90-96$ & very severe \\
\hline $31-45$ & $97-100$ & \\
\hline \hline
\end{tabular}


Riley followed 17 high risk children to use as his data base. After a two year period he continued to monitor 6 of the children because of potential stuttering leaving only 11 children who did not become stutterers within two years after they were first examined for him to base his normative data on (Riley, 1981). Riley (1981) warns that additional research is needed but claims the information provided in the SPI can be used as a guideline for clinicians evaluating disfluent children.

In conclusion, the literature indicates there is a need for further research on normally developing young children to assist clinicians in accurately discriminating between incipient stutterers and normally disfluent children. 
CHAPTER III

METHODS

Subjects

Twenty 33-39 month old normal children including ten girls and ten boys were selected from the Portland area to participate in the study. All of the children were considered to be low risk for stuttering chronicity as was determined by the primary caregivers assessment of the child as being normal in their speech and language development. Any child considered to be a stutterer by the parent was excluded from the study. None of the parents were concerned about stuttering and the investigator was in agreement. The girls ranged in age from 33 to 38 months with a mean of 36 months. The boys ranged from 330 to 38 months with a mean of 37 months. The mean age of boys and girls was 36 months. No attempt was made to control socioeconomic status. The children met the following criteria:

1. English as the primary language spoken in the home.

2. Pass a $25 \mathrm{~dB}$ hearing screening at 1000, 2000, and $4000 \mathrm{~Hz}$. or no history of chronic middle ear infections or allergies. 
3. No known hearing loss as reported by the primary caregiver.

4. No known neurological impairment.

5. No prior intervention for fluency nor sought counseling for fluency concerns.

6. The primary caregiver is not concerned about fluency.

7. Speech intelligibility of at least 75 percent.

8. No cold at the time of testing.

9. A mean length of response of at least 2.5 words.

10. Able to attend to a low stress task for 15 minutes.

\section{Subject Eligibility procedures}

Parent letters (Appendix A) and permission forms and questionnaires (Appendix B) obtaining information about the child's fluency characteristics and medical, developmental, and family history were distributed at the child's day care center or filled out by the investigator during a phone interview if the child did not attend a participating day care center. The investigator reviewed the questionnaires and set up appointments at Portland State University Speech Communication Department Clinic for children whose parents answered yes to question 1 and no to questions 3 through 5 (see questionnaire, Appendix B). Children whose parents answered yes to question number 2 were informed at this time 
that their child needed to pass a hearing screening in order to participate in the study.

When the child arrived at Portland State University, an informal language sample was obtained to determine if the child's mean length of response was at least 2.5 words and speech intelligibility was at least 75 percent. Next, a hearing screening was administered to children who had a history of ear infections or an ear infection in the last six months. The Peabody Picture Vocabulary Test - Revised (Dunn \& Dunn, 1981) was also given for future research purposes.

\section{Speech Sample Procedures}

Once it was established the child qualified for the study, a fifteen minute speech sample was obtained at Portland State University. This was done by having the child interact with the investigator during free play in a clinical room with a one way mirror using a standard set of toys and open ended questions (see Appendix $C$ ). The speech sample was video taped by a graduate student who had trained on the equipment. The video equipment was placed in an observation room on the other side of the one way mirror in order to reduce distraction.

\section{Scoring procedures}

The speech sample was transcribed verbatim and the first 25 words were omitted, as per Riley's instruction. To 
answer the first question, what are the types and frequencies of disfluencies demonstrated by normal 33-39 month old children, the frequencies and types of disfluencies of the next 100 words were analyzed on a scoring sheet with coded columns representing specific types of disfluencies following the utterance. In addition there was a column for the total number of disfluencies (see Appendix D) .

To answer the second question, how do the scores of normal 33-39 month old children distribute on the SSI, the Stuttering Severity Instrument manual was used as a guideline (see Appendix E). After omitting the original 25 words the next 100 words were scored according to the scoring procedures outlined in the SSI manual. The SSI calculates the severity score by adding together total frequency, duration and physical concomitants scores. These three separate scores are determined by comparing the child's total frequency, duration and physical concomitants to scoring scales and finding the corresponding task score. After calculating the SSI scores a graph was made to show how the scores of children distributed on the SSI.

\section{Reliability}

Interjudge reliability was determined to be 99 percent by having the investigator and two speech pathology graduate students transcribe 10 utterances of five video tapes using the same code described under scoring procedures, Appendix 
D. Someone who was not familiar with the tapes arbitrarily chose the segments and made content transcripts. See Appendix F. Before transcribing the tapes, the scorers were trained and given content transcripts. See Appendix G. Intrajudge reliability was determined by scoring 3 identical segments twice two weeks apart. It was 100 percent by the investigator and 99 and 97 percent by the two other judges.

\section{Data Analysis}

To answer the first question, what are the types and frequencies of disfluencies demonstrated by normal 33-39 month old children, means and standard deviations were calculated for each type of disfluency and for the overall frequency of disfluencies.

To answer the second question, how do the scores of normal 33-39 month old children distribute on the SSI, SSI scores were calculated according to the guidelines set forth in the manual for each child. 
CHAPTER IV

RESULTS AND DISCUSSION

Results

In order to determine the types and frequencies of disfluencies demonstrated by normal 33-39 month old children means and standard deviations were calculated on the frequencies of the specific types of disfluencies demonstrated by twenty 33-39 month old children and on the overall frequency of disfluencies. As can be seen in Table VII, the boys produced revision-incomplete phrases 1.70 times per 100 words and whole word repetitions 1.60 times per 100 words while the boys and girls combined produced revision-incomplete phrases 1.5 times per 100 words and whole word repetitions 1.60 times per 100 words. These were the most frequently occurring types of repetitions for these two groups. The girls produced revision-incomplete phrases and interjections the most frequently. Both of these types of disfluencies occurred 1.30 times per 100 words in their speech. The boy, girls, and boys and girls combined produced dysrhythmic phonations and tense pauses the least frequently. The boys produced dysrhythmic phonations .50 per 100 words and tense pauses 0 times per 100 words, the 


\section{TABLE VII}

DISFLUENCIES DEMONSTRATED BY

33-39 MONTH OLD

NORMAL CHIIDREN

\begin{tabular}{|c|c|c|c|c|c|c|c|c|}
\hline & RIC & INT & PR & WR & PWR & DPV & $\mathrm{TP}$ & TOTAL \\
\hline $\begin{array}{l}\text { Girls } \\
\text { Mean }\end{array}$ & 1.30 & 1.30 & 1.00 & 1.00 & .50 & .30 & 0.00 & 5.40 \\
\hline S.D. & $(1.57)$ & $(1.70)$ & $(.94)$ & $(1.30)$ & $(.53)$ & $(.67)$ & $(0.00)$ & $(2.88)$ \\
\hline $\begin{array}{l}\text { Boys } \\
\text { Mean }\end{array}$ & 1.70 & 1.20 & .90 & 2.00 & 1.00 & .50 & 0.00 & 7.30 \\
\hline S.D. & $(1.77)$ & $(1.23)$ & $(1.10)$ & $(1.40)$ & $(.94)$ & $(.53)$ & $(0.00)$ & $(2.91)$ \\
\hline $\begin{array}{l}\text { Boys \& } \\
\text { Girls } \\
\text { Mean }\end{array}$ & 1.50 & 1.25 & .95 & 1.60 & .75 & .40 & 0.00 & 6.35 \\
\hline S.D. & $(1.60)$ & $(1.40)$ & $(.99)$ & $(1.40)$ & $(.78)$ & $(.60)$ & $(0.00)$ & $(2.98)$ \\
\hline $\begin{array}{ll}\text { RIC: } & r \\
\text { INT: } & i \\
\text { PR: } & \quad \\
\text { WR: } & \quad h\end{array}$ & $\begin{array}{l}\text { revision-ir } \\
\text { interjectic } \\
\text { phrase repe } \\
\text { word repeti }\end{array}$ & $\begin{array}{l}\text { omplete } \\
\text { ition } \\
\text { ion }\end{array}$ & phrase & & $\begin{array}{l}\text { PWR: } \\
\text { DP: } \\
\text { TP: }\end{array}$ & $\begin{array}{l}\text { part- } \\
\text { dysrhy } \\
\text { tense }\end{array}$ & $\begin{array}{l}\text { ord rep } \\
\text { thmic p } \\
\text { pause }\end{array}$ & $\begin{array}{l}\text { ition } \\
\text { nation }\end{array}$ \\
\hline
\end{tabular}


girls produced dysrhythmic phonations .30 times per 100 words and tense pauses 0 times per 100 words and the girls and boys combined produced dysrhythmic phonations .40 per 100 words and tense pauses 0 times per 100 words.

In order to determine how the scores of normal 33-39 month old children distribute on the stuttering Severity Instrument the speech of twenty normal 33-39 month old children was evaluated using the stuttering Severity Instrument's manual as a guideline. The results, as indicated in Table VIII show the children were diagnosed as very mild and mild stutterers on the stuttering Severity Instrument. Five children were diagnosed as very mild and fell into the $0-4$ th percentile group, eleven children diagnosed as mild fell into the 5-11th percentile group and four children also diagnosed as mild fell into the 12-23rd percentile group. Considering the boys and girls separately, the boys' scores ranged from 7-11 with a mean score of 8.2 , while the girls' scores ranged from 0-8 with a mean score of 5.6 .

\section{Discussion}

In regards to the first question, what are the types and frequencies of disfluencies demonstrated by normal 33-39 month old children, the types and frequencies of disfluencies demonstrated by the children in this study tend to support previous findings. The types of disfluencies observed agreed with the previous literature and although 
TABLE VII I

SSI SCORES OF NORMAL 33-39 MONTH OLD CHILDREN

\begin{tabular}{|c|c|c|c|c|c|}
\hline & & SEX & SSI SCORE & $\begin{array}{ll}\text { SSI } & \text { SEVERITY } \\
& \text { RATING }\end{array}$ & PERCENTILE \\
\hline Child & 1 & $F$ & 5 & very mild & $0-4$ \\
\hline Child & 2 & M & 8 & $\operatorname{mild}$ & $5-11$ \\
\hline Child & 3 & $\mathbf{M}$ & 7 & $\operatorname{mild}$ & $5-11$ \\
\hline Child & 4 & $\mathrm{~F}$ & 5 & very mild & $0-4$ \\
\hline Child & 5 & $\mathbf{F}$ & 5 & very mild & $0-4$ \\
\hline Child & 6 & $\mathrm{~F}$ & 7 & $\operatorname{mild}$ & $5-11$ \\
\hline Child & 7 & $\mathbf{F}$ & 7 & $\operatorname{mild}$ & $5-11$ \\
\hline Child & 8 & $\mathbf{M}$ & 7 & $\operatorname{mild}$ & $5-11$ \\
\hline Child & 9 & $F$ & 0 & very mild & $0-4$ \\
\hline Child & 10 & $\mathbf{M}$ & 11 & $\operatorname{mild}$ & $12-23$ \\
\hline Child & 11 & $\mathbf{M}$ & 9 & $\operatorname{mild}$ & $12-23$ \\
\hline Child & 12 & M & 9 & $\operatorname{mild}$ & $12-23$ \\
\hline Child & 13 & M & 8 & $\operatorname{mild}$ & $5-11$ \\
\hline Child & 14 & M & 7 & $\operatorname{mild}$ & $5-11$ \\
\hline Child & 15 & $\mathrm{~F}$ & 7 & $\operatorname{mild}$ & $5-11$ \\
\hline Child & 16 & $F$ & 8 & $\operatorname{mild}$ & $5-11$ \\
\hline Child & 17 & $F$ & 8 & $\operatorname{mild}$ & $5-11$ \\
\hline Child & 18 & $\mathrm{~F}$ & 5 & very mild & $0-4$ \\
\hline Child & 19 & M & 9 & mild & $12-23$ \\
\hline Child & 20 & $M$ & 7 & $\operatorname{mild}$ & $5-11$ \\
\hline
\end{tabular}


the frequency counts were generally lower than wexler and Mysak's (1982) and more closely approximated Yairi's (1981) once the standard deviations were taken into account there was not a large discrepancy between frequency counts. As originally pointed out by DeJoy and Gregory (1985), this study confirmed the standard deviations all approached or exceeded the means.

The types of disfluencies observed in order of frequency were whole word repetitions, revision-incomplete phrases, interjections, phrase repetitions, part-word repetitions, dysrhythmic phonations, and tense pauses (see Table IX).

Wexler \& Mysak (1982) and Yairi \& Clifton (1982)

report normal preschool children demonstrate more interjections and revision-incomplete phrases than any other types of disfluencies. The children in this study not only demonstrated more revision-incomplete phrases and interjections but also more whole word repetitions than other types of disfluencies. This agrees with Riley's and Adams' belief that normally disfluent children tend to demonstrate more whole-word repetitions than part-word repetitions.

Part-word repetitions, dysrhythmic phonations and tense pauses were the most unfrequently observed types of disfluencies in this study. This agrees with Yairi \& Clifton (1982) and Wexler \& Mysak (1982) who report that 
TABLE IX

RANK ORDER OF TYPES OF DISFLUENCIES

DEMONSTRATED BY 33-39 MONTH OLD

NORMAL CHILDREN

Type of Disfluency

Whole word repetitions

Revision-incomplete phrase

Interjections

Phrase repetitions

Part-word repetitions

Dysrhythmic phonations

Tense pauses
Frequency

1.60

(1.40)

1.50

(1.60)

1.25

(1.40)

.95

$(.99)$

.75

(.78)

.40

$(.60)$

0.00

$(0.00)$ 
part-word repetitions and dysrhythmic phonations are among the least frequently occurring types of disfluencies seen in preschoolers. It also is in agreement with Riley and Adams who believe part-word repetitions, prolongations and tense pauses are more characteristic of incipient stutterers than normally disfluent children.

This study also was in agreement with past studies in regards to the frequency of disfluencies exhibited by normal preschool children. The mean number of disfluencies in this study was 6.35 disfluencies per 100 words. Adams (1977), Yairi \& Lewis (1984) and Yairi \& Clifton (1982) all report normally disfluent children tend to be disfluent less than 10 percent of the time. Overall, in terms of types and frequencies of disfluencies the results of this study support past studies.

In regards to the second question, how will the scores of normal 33-39 month old children distribute on the Stuttering Severity Instrument, all of the children scored as very mild or mild stutterers even though the SSI does not take into account revision-incomplete phrases, interjections and phrase repetitions in the overall score which are three of the four most frequently observed types of disfluencies in normally disfluent children's speech. The normal repetitions that caused children to score as stutterers were primarily whole-word repetitions of one syllable and partword repetitions. Although some of the children 
demonstrated some part-word repetitions none of the children produced more than two unit repetitions per part-word repetition which Adams (1987) reports as one of five factors differentiating the incipient stutterer from the normally disfluent child.

A clinician who is concerned about a child's falling into the very mild or mild range of the SSI needs to further examine the child's speech before labeling him as a stutterer. As mentioned before, whole word repetitions of one syllable and part-word repetitions were the primary characteristics responsible for normally disfluent children scoring as incipient stutterers. None of the normally disfluent children demonstrated physical concomitants other than distracting sounds. In addition, the highest score in this category was only a one which represented a few interjections which would not have been noticed by a casual observer. This may indicate a child who demonstrated physical concomitants such as facial grimaces, head movement or extremities movement is more likely to become a stutterer rather than pass through this developmental stage.

Another possible indicator of chronicity is duration. All of the disfluencies observed by the normally disfluent children were fleeting. Many of them occurred so quickly they would not even be noticed by a casual observer. This may indicate the clinician needs to be more concerned about 
children whose disfluencies continue beyond a fleeting moment.

The results of this study indicate when the SSI is used with 33-39 month old children it needs to be used cautiously. Children falling into the very mild or mild range need to be evaluated more thoroughly to determine if monitoring, counseling or intervention is warranted. Children demonstrating more disfluencies than two standard deviations above the mean or 12.3 disfluencies per 100 words but free of physical concomitants and durations longer than a fleeting moment should be considered at a high risk to become stutterers. The clinician should provide the families of these children with environmental counseling and periodic follow up checks to determine whether intervention will be necessary.

Intervention should be considered for children who score above mild on the SSI or demonstrate more than one of the following characteristics: more than 9.33 whole and part-word disfluencies per 100 words, disfluencies longer than a fleeting moment, physical concomitants, more than two unit repetitions per repetition, dysrhythmic phonations and tense pauses. 


\section{CHAPTER V}

\section{SUMMARY AND IMPLICATIONS}

\section{Summary}

The onset of stuttering usually occurs between two and six years which is the same time most children exhibit normal disfluencies often making it difficult to differentiate between normally disfluent children and incipient stutterers (DeJoy \& Gregory, 1985). Clinicians need information on the types and frequencies of disfluencies exhibited by normal preschool children in order to determine if a child is more likely to be an incipient stutterer or normally disfluent child. Some clinicians feel uncomfortable relying on past literature since there is a Iimited amount of information available and the studies have shown a considerable amount of variability in the types and frequencies of disfluencies demonstrated by children.

The SSI is an instrument that purports to determine the severity of stuttering, however, it does not distinguish at its lower levels the normally disfluent person from the beginning stutterer. This is especially relevant in the preschool child, an age at which an early accurate diagnosis is often difficult to make. The chief problem with the 
instrument is that all children are labeled stutterers. In addition, no data on normal preschool children has been published in regard to their performance on the SSI. The purpose of this study was to investigate the disfluency characteristics of normal 33-39 month old children in order to determine the differential role of the SSI with young children. Twenty 33-39 month old normal children participated in the study. Means and standard deviations for the types of disfluencies and SSI scores were calculated for each child. The types and frequencies of disfluencies demonstrated tend to support past literature with whole-word repetitions, revision-incomplete phrases and interjections occurring the most frequently.

All of the children scored as very mild or mild stutterers on the SSI. The normal repetitions that caused children to score as stutterers were primarily whole-word repetitions of one syllable and part-word repetitions. None of the normally disfluent children demonstrated physical concomitants or durations longer than a fleeting moment. It appears that treatment should be considered for children scoring above mild on the SSI or demonstrating dysrhythmic phonation, tense pauses, physical concomitants and durations longer than a fleeting moment.

\section{Clinical Implications}

This study has many implications for clinicians making decisions as to whether a child is normally disfluent or an 
incipient stutterer. The stuttering Severity Instrument does not adequately differentiate between the normal disfluent child and very mild or mild stutterer making it necessary for the clinician to examine an individual's speech characteristics regardless of whether the SSI is used.

The results of this study in regards to the normal types and frequencies of disfluencies present in preschooler's speech indicate whole word repetitions, revision-incomplete phrases and interjections are the predominate types of repetitions occurring in normal children's speech while tense pauses and dysrhythmic phonations rarely occur in normal children's speech. In addition, neither tense pauses nor dysrhythmic phonations were responsible for normal children scoring as stutterers on the SSI. This may indicate the clinician needs to be more concerned about children demonstrating tense pauses and dysrhythmic phonations than those only demonstrating wholeword repetitions, interjections and revision-incomplete phrases.

Other characteristics which may be predictors of chronicity of stuttering are physical concomitants and duration. These characteristics also did not play a role in normal children scoring as stutterers on the SSI indicating they may be good discriminators between the normally disfluent child and incipient stutterer. 
In summary, the results of this study indicate the clinician needs to analyze a child's speech to determine whether it possesses the characteristics of an incipient stutterer or normally disfluent child. A clinician should consider treatment for a child scoring above mild on the SSI or whose speech is characterized by tense pauses, dysrhythmic phonations, long durations, physical concomitants and more than two unit repetitions per repetition.

Research Implications

The results of this study indicate a need for further research on normal disfluencies and methods of differentially diagnosing preschoolers. Future research might include longitudinal studies on high and low risk children examining the differences between the types and frequencies of disfluencies exhibited by the two groups and by the children who outgrow their disfluencies and those that become stutterers. In addition, a diagnostic instrument might be administered to these children and the scores of both the high and low risk children and the children who outgrow their disfluencies and the ones who become stutterers could be compared. Another research project might involve collecting normative data for preschool children on the SSI, SPI and other commonly used diagnostic instruments to determine subclinical cutoff points and characteristics that the clinician may want to disregard when evaluating a child. 


\section{BIBLIOGRAPHY}

Adams, M. (1977). A clinical strategy for differentiating the normally nonfluent child and the incipient stutterer. Journal of Fluency Disorders, 2, 141-148.

Adams, M. (1980). The young stutterer: Diagnosis, treatment and assessment of progress. Seminars in Speech, Language and Hearing, 1, 289-298.

Adams, M. (1984). The young stutterer: Diagnosis, treatment and assessment of progress. In $\mathrm{W}$. Perkins (ed.), Stuttering Disroders. New York: ThiemeStratton Inc.

Branscom, M., Hughes, J. and Oxtoby, E.T. (1955). Studies of non-fluency in speech of preschool children. In $W$. Johnson (ed.), stuttering in children and adults. Minnesota: University of Minnesota.

Curlee, R.F. (1980). A case selection strategy for young disfluent children. In W.H. Perkins (ed.), Stuttering Disorders. New York: Thieme Stratton Inc.

DeJoy, D. and Gregory, H. (1985). The relationship between age and frequency of disfluency in preschool children. Journal of Fluency Disorders, 10, 107-122.

Dunn, L. and Dunn, L. (1981). Peabody Picture Vocabulary Test-Revised. Circle Pines, MN: American Guidance Service.

Fraser, M. (1985). Self-Therapy for the Stutterer. Memphis, Tennessee: Speech Foundation of America.

Hopper, R. and Naremore, R.S. (1978). Children's Speech. New York: Harper and Row, Publishers.

Peterson, H.A. and Marquardt, T.P. (1981). Appraisal and Diagnosis of Speech and Language Disorders. New Jersey: Prentice-Hall, Inc.

Pindzola, R.H. and White, D.T. (1986). A protocol for differentiating the incipient stutterer. Language, Speech and Hearing Services in Schools, 1, 2-11. 
Riley G. (1972). A stuttering severity instrument for children and adults. Journal of Speech and Hearing Disorders, 37, 314-320.

Riley G.D. (1981). Stuttering Predition Instrument for Young Children. Tigard, Oregon: C.C. Publications, Inc.

Van Riper, C. (1971). The nature of stuttering. Englewood Cliffs, NJ: Prentice-Hall, Inc.

Wexler, K. and Mysak, E. (1982). Disfluency characteristics of 2,4 , and 6 year old males. Journal of Fluency Disorders, 7, 37-46.

Williams, D., Silverman, F. and Kools, J. (1968). Disfluency behavior of elementary school stutterers and nonstutterers: The adaptation effect. Journal of Speech and Hearing Research, 11, 622-630.

Wingate, M. (1964). A Standard definition of stuttering. Journal of Speech and Hearing Research, 490-495.

Yairi, E. (1981). Disfluency of normally speaking two-yearold children. Journal of Speech and Hearing Research, $24,490-495$.

Yairi, E. and Clifton, N. (1972). Disfluent speech behavior of preschool children, high school seniors, and geriatric persons. Journal of Speech and Hearing Research, 15, 714-719.

Yairi, E. and Lewis, B. (1984). Disfluencies at the onset of stuttering. Journal of Speech and Hearing Research, 154-159. 
APPENDIX A

PARENT LETTERS

I am a graduate student at Portland State University investigating the fluency characteristics of normal preschool children. Nearly all children have interruptions in their flow of speech which do not warrant concern or intervention. These interruptions are called normal disfluencies. I am trying to find out the types and frequencies of these disfluencies and whether an instrument used for evaluating fluency is appropriate for this age range.

This study can be accomplished by a 15 minute video taped interview with your child talking with me. The video taped session will take place at Portland State University at a time convenient for you and the department. Your child's name will not be used in reporting the results and the video tapes will only be available to authorized university personnel. Your child can refuse to participate in this study or withdraw from participation at any time without penalty or jeopardizing their relationship with the preschool or day care center.

Before the video taped session, your child will receive a brief test of word meaning called the Peabody Picture Vocabulary Test Revised for future research purposes. You will also be asked to complete a brief questionnaire about your child's speech and language development, medical history, your family and any stuttering you have observed in family members. If you have any questions as a result of your participation in this study please contact Robert Tinnin, Office of Graduate Studies and Research, 105 Neuberger hall, Portland State University, 229-4323.

Please complete the information on the attached sheet, indicating your approval and willingness to participate in this study and then return this form to me immediately in the envelope provided. It is important I schedule the taping sessions as soon as possible. Please call me at 224-3661 if you have any questions. I appreciate your cooperation. 


\section{APPENDIX B}

CONSENT FORM

Child's Name:

Birthdate:

Age :

Parent's Name:

Address :

Phone Number:

1. Is English the primary language spoken in your home? Yes No

2. Does your child tend to get ear infections or has she/he had an ear infection within the last six months? Yes No

3. Has your child ever been diagnosed with any of the following:

Developmental delay Yes Mental retardation Neurological impairment Yes Orthopedic or physical handicap yes Allergies Yes No Hearing loss Yes

4. Have you ever been concerned about your child's fluency or sought counseling for fluency concerns? Yes No

5. Has your child ever received speech therapy for stuttering?

Yes No

I hereby give my permission for my child, to participate in this study. My child may attend a video taping session and participate in a brief test of word meaning. I will complete the questionnaire and I understand I can withdraw my permission at any time during this study without penalty or jeopardizing my relationship with the preschool or day care center. 


\section{APPENDIX C}

\section{LIST OF STIMULI}

\section{TOYS}

1 telephone

2 cars

2 medium-sized rubber toys

1 wind-up toy

2 puppets

2 dolls

Fischer Price Play House

Tea and plate set

\section{QUESTIONS}

Who lives at your house?

Tell me about them.

What is your bedroom like?

Do you have any pets? Tell me about them.

What do you do to take care of a pet?

What do you do at school?

Tell me about your friends.

What did you do for your last birthday?

Tell me about your favorite TV show.

Tell me how to brush your teeth.

Tell me how to make a peanut butter and jelly sandwich.

\section{PROMPTS}

Tell me more.

What else?

Why?

Mmm hmm

Tell me about it.

Oh, wow. 
APPENDIX D

DISFLUENCY RECORD

CLIENT'S NAME

AGE

Utterance NOW RIC INT PR WR PWR DP TP TOTAL

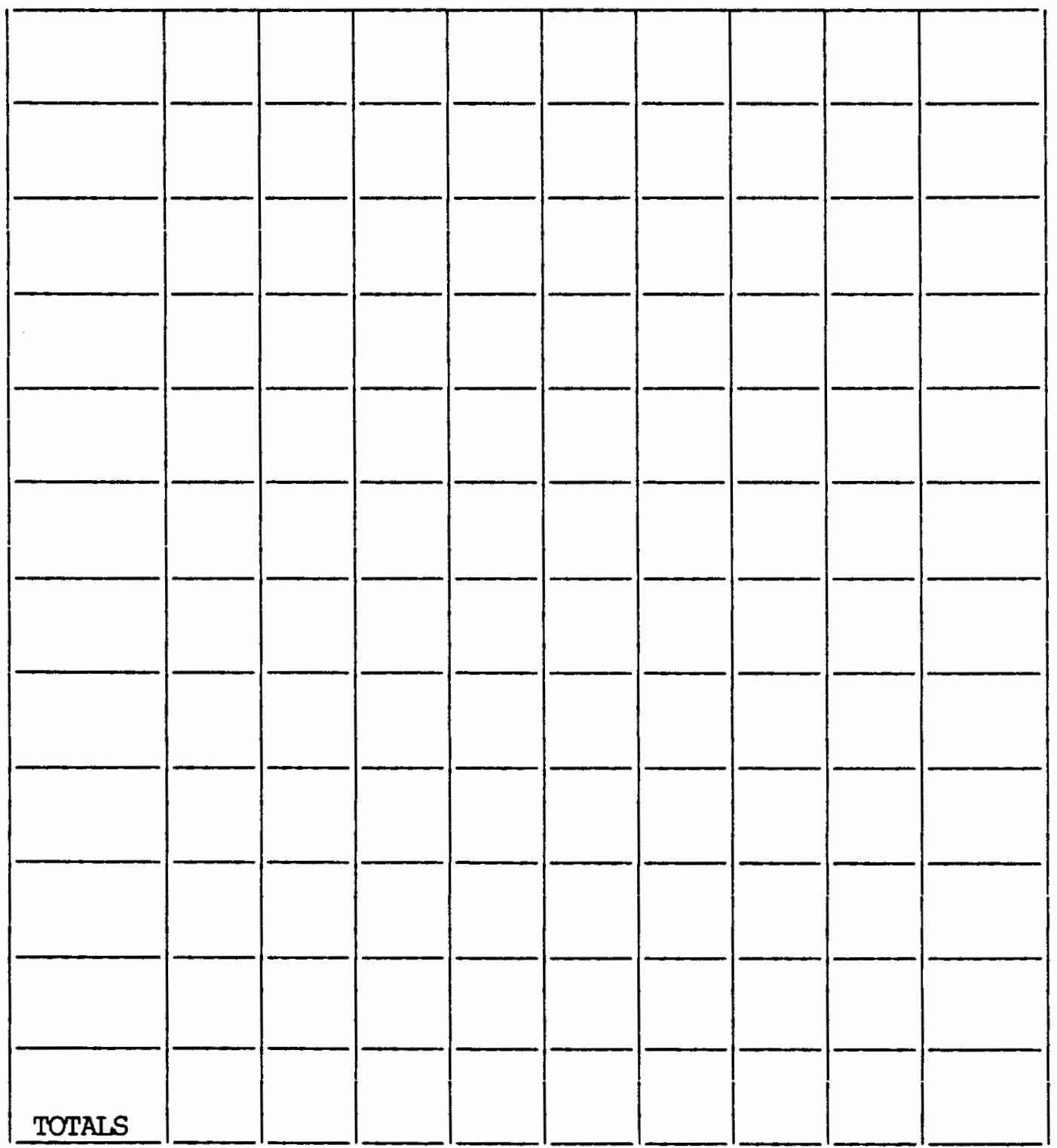

CODES: NOW: number of words INT: interjection PR: phrase repetition WR: word repetition FWR: part-word repetition DP: dysrhythmic phonations TP: tense pauses 


\begin{abstract}
APPENDIX E
THE SSI'S MANUAL ADMINISTRATION INSTRUCTIONS

(Riley, 1972)

\section{STUTTERING SEVERITY INSTRUMENT \\ ADMINISTRATION INSTRUCTIONS}

Administering the SSI to Nonreaders

Any child who is below the third grade in his reading ability is included in this nonreader group. The child is shown a cartoon sequence which tells a story but which has had the captions removed. He is asked to "Tell the story that goes with these pictures." The verbalizations should be tape-recorded. As the child begins to talk, the examiner should make a dot for each word spoken fluently and a slash mark for each word stuttered, thus : $/ \ldots / \ldots / \ldots / \ldots / \ldots /$ ../.../.../../, and so on. Reliability can be tested by repeated listening to the taped record. Any silent or audible prolongation and any repetition of a sound or syllable is considered a stuttered block. Whole word and phrase repetitions and rephrasing are not considered blocks. A total sample of a least 150 words is required for the frequency count. After the picture task the child should be engaged in conversation. If the child's stuttering is noticeably more severe during conversation than it was during the story, obtain a "conversation" frequency count and note that it has been used. The estimate of duration of the "three longest blocks" and observations of "physical concomitants" are based on the entire sample.

Duration is estimated on the following scale:

$\begin{array}{ll}\text { Fleeting } & 1 \text { point } \\ \text { One-half sec } & 2 \text { points } \\ \text { One full sec } & 3 \text { points } \\ 2.9 \text { sec } & 4 \text { points } \\ 16.30 \text { sec } & 5 \text { points } \\ 30.60 \text { sec more } & 6 \text { points } \\ 60 \text { sec or more } & 7 \text { points }\end{array}$

Blocks of 10 seconds and more should be timed by a sweep second hand on a watch or clock. Stopwatch accuracy is not required. 
Physical concomitants associated with the blocks or with attempts to avoid blocking should be scored on the following scale: $0=$ none, 1 = not noticeable unless looking for it, 2 = barely noticeable to casual observer, 3 = distracting, 4 = very distracting; 5 = severe and painful looking. Only observable phenomena should be scored. The phenomena are categorized as follows:

1. Distracting Sounds. This category includes any sound which accompanies the stuttering in addition to phonemes. For example, the child may continually clear his throat or may say /a:/ repeatedly. These sounds count, even though they are not part of the block itself. Other common sounds include noisy breathing, whistling noises, sniffing, blowing, and clicking sounds. The evaluator must determine the extent to which these sounds are distracting to a listener.

2. Distracting Facial Grimaces. Any abnormal movement or tension about the face counts in this category. Examples of abnormal facial behavior are pressing lips together tightly, tensing jaw muscles, blinking eyes or partially closing eyes, protruding tongue, and incoordinated jaw movement.

3. Distracting Head Movements. These movements generally consist of turning the head away from the listener to avoid eye contact, looking down at feet, scanning the room, and looking up at the ceiling.

4. Distracting Movements of the Extremities. Any general body movement, such as shifting position in the chair, counts in this category, as does any specific movement of a limb, such as a foot-tapping. Excessive movement of hands about the face, fidgeting with something in the hand, and swinging an arm are also common.

The judgment about duration and physical concomitants is recorded directly on the test form as it is made, by circling the appropriate number. The frequency count and the total are computed later. To arrive at a frequency count, skip the first 25 words and then count the number of stuttered words (marked on the page) in the next 100 words of the sample. Bracket the 100 words used. This count is the number of blocks in 100 (a percentage). The table on the test form can be used to convert this percentage into a task score. If fewer than 100 words have been spoken, the percentage must be computed. In either case, do not include the first 25 words in the frequency count. The result of the count converted to a task score will yield a numerical value between zero and 18. Record this number in the box to the right of the page marked "Total Frequency Score." 
The task score for "Duration," which has been circled, should be recorded in the box marked "Total Duration Score."

A separate judgement was made for each anatomical area (facial, head and extremity) and a judgment was made for distracting sounds. Each of these judgments was between zero and five, based on the evaluating scale add the four circled numbers together and a "Total physical Concomitant" score between 0 and 20 is obtained, to be recorded in the right-hand box.

By adding the three box scores together a "Total overall score" is obtained. The severity of this child's stuttering can be ascertained by comparing his score to the normative data presented in Table 1 . It may be described as a percentile, or by an adjective which describes the level of severity as very mild, mild, moderate, severe, or very severe.

Table 1. Percentile and severity equivalents of SSI raw scores $(\mathrm{N}=109)$.

Total

Score

Percentile

Severity

$\begin{array}{cc}0-5 & 0-4 \\ 6-8 & 5-11 \\ 9-13 & 12-23 \\ 14-15 & 24-40 \\ 16-19 & 41-60 \\ 20-23 & 61-77 \\ 24-27 & 78-89 \\ 28-30 & 90-96 \\ 31-45 & 97-100\end{array}$

Very Mild

Mild

Moderate

Severe

Very Severe 


\section{APPENDIX F \\ INSTRUCTIONS FOR SELECTION OF CONTENT TRANSCRIPTS FOR RELI ABILITY TEST ING}

Video tapes have been made of a child and an adult interacting in a play situation. The children's conversations in these video tapes have been transcribed verbatim and these transcripts are what you will be working from. You are responsible for extracting 10 utterances from each of the eight transcripts you are given and forming a content transcript for each one. A content transcript can be defined as the basic information of an utterance provided by the child, deleting any type of disfluency, such as: interjections, part-word repetitions, whole word repetitions, revision-incomplete phrases, prolongations and phrase repetitions, without the addition of any additional words that the child did not specifically speak. There are specific guidelines to follow when developing these content transcripts.

A. Guidelines

1. Type one utterance per line.

2. Use utterances 10-19.

3. Additional words should not be added to the utterances, only use those words which are present in the transcripts. 
4. It may be necessary with some utterances to include the full utterance that was presented on the transcript. This will occur when the utterance does not consist of any disfluencies.

5. Disfluencies in the basic transcript should not be included in the content transcript, this includes: phrase repetitions, revision-incomplete phrases, part-word repetitions, whole word repetitions, prolongations and interjections. For example, "I-II am going" would be written "I am going" and "uh I need uh I need to talk" would be written "I need to talk."

6. In transcribing revision-incomplete phrases into content episodes only include the most complete form of the utterance. For example, "It is a ze - it is a giraffe" would be written "It is a giraffe" and "please set the chair - table" would be written "Please set the table."

7. An unintelligible utterance would be labeled as an unintelligible utterance. If only part of the utterance is unintelligible and the rest has been transcribed, label the unintelligible segment and include the transcribed section in its most completed form.

8. Any additional sounds or pulses at the beginning, middle or end of the episode should not be included in the content transcript.

B. Examples of Full Transcription and Corresponding Content Transcription

Full Transcription

1. I don't know

2. I he I already tell him

3. unintelligible episode

4. yah

5. You have a tea party with us?

6. w-w-where is she

7. I think sh-she got to sit

\section{Content Transcription}

1. I don't know

2. I already tell him

3. unintelligible episode

4. yah

5. you have a tea party with us?

6. where is she

7. I think she got to sit 
8. and when she wakes (rest unintelligible)
8. and when she wakes (rest unintelligible) 


\section{APPENDIX G \\ INSTRUCTION TO RELIABILITY JUDGES}

PART ONE: Instructions for Selection of Content Transcripts for Reliability Testing

Read the attached instructions to the individual responsible for preparation of content transcription for reliability testing.

\section{PART TWO: General Instructions}

You will be given five partially complete transcripts. These transcripts contain 10 utterances and are only partially complete. The transcripts do not include any type of disfluency such as: phrase repetitions, revisionincomplete phrases, interjections, part-word repetitions, whole-word repetitions, dysrhythmic phonations and tense pauses. The transcripts contain only the content of the utterances. It is very important not to accept the utterance as correct just because you are cueing into key words, listen to the entire utterance and see if you agree with all the words that have been given to you, then add the additional words you are hearing along with the disfluencies.

The purpose of this reliability testing is to determine the investigator's accuracy at identifying whole- 
word repetitions, part-word repetitions, dysrhythmic phonations, revision-incomplete phrases, interjections, phrase repetitions, tense pauses, duration of blocks and physical concomitants. The following are definitions of these terms:

1. Whole word repetitions: The repetition of an entire word.

2. Part-word repetition: The repetition of a sound or syllable unit which is less than the entire word. For example, s-s-sun is a sound repetition and ta-ta-table is a syllable repetition.

3. Dysrhythmic phonations: The audible or silent continuation of a sound or articulatory posture which disturbs or distorts the normal rhythm or flow of speech (Williams, Silverman, \& Kool, 1968). Dysrhythmic phonations are also referred to as prolongations and include broken words (Yairi, 1981).

4. Revision-incomplete phrase: Making a new version of a phrase to alter a thought, word or idea. For example, the cat - the dog ran.

5. Interjections: A sound inserted within the flow of speech which is not part of the message. For example, uh, er, um, well - I mean.

6. Phrase repetition: The unintentional repetition of two or more words.

7. Tense pause: A disfluency that occurs between words, part-words and nonwords when at the between point in question there are barely audible manifestations of heavy breathing or muscular tightening. The same phenomena within a word would place the word in the category of dysrhythmic phonation (Williams, Silverman, \& Kool, 1968).

8. Duration of blocks: The estimated length of each block that lasts one second or longer.

9. Physical concomitants: The visible and audible phenomena which accompany the stuttered speech (Riley, 1972). Riley (1972) lists four categories of physical concomitants: distracting sounds (e.g., hissing noise, throat clearing), distracting facial grimaces (e.g., eye 
blinks, tongue protrusion), distracting head movements (e.g., turning head from listener, looking at floor), and distracting movements of the extremities (e.g. foottapping, arm swaying).

PART THREE: Procedures for Transcription and Identification of Disfluencies

An individual not involved in this study has prepared content transcripts (Appendix F). Reliability raters will be given these transcripts. A technician will then play the corresponding segment of the video tape that matches the content transcripts, the technician will initially show the reliability raters all 10 utterances at once while the raters observe the utterances in their entirety. The technician will then play the video segment again only showing the raters one utterance at a time. The raters will be responsible for filling in all missing parts of the transcripts, including words that have been deleted and all disfluencies. It should also be noted that the raters are responsible for making any changes in transcripts due to errors made by the individual selecting content transcripts. The following rules should be used when transcribing and identifying disfluencies.

1. Raters are only responsible for identification of whole word repetitions, part-word repetitions, dysrhythmic phonations, revision-incomplete phrases, interjections, phrase repetitions, tense pauses, duration of blocks and physical concomitants.

2. Use the following key to identify disfluencies:

pwr: part-word repetition

ww: whole-word repetition

rip: revision-incomplete phrase 
dp: dysrhythmic phonation

tp: tense pause

pr: phrase repetition

int: interjection

pc1: physical concomitant - distracting sounds

pc2: physical concomitant - facial grimaces

pc3: physical concomitant - head movement

pc 4: physical concomitant - extremities movement

3. No matter how many times a whole word or part-word is repeated it is only credited as one disfluency.

4. An utterance may have a combination of any of the disfluency types and should be credited as separate disfluencies if this occurs. For example, Ky-Kyle Kyle would be scored as 1 part-word repetition and 1 wholeword repetition. Th-the-the table-the tablet would be scored as 1 part-word repetition 1 whole-word repetition and 1 revision-incomplete phrase.

5. Repetitions of the first part of a contraction such as it-it's and I-I'm should be credited as a part-word repetition since the contraction functions as a single word for the young child and was calculated as one word when determining the word count for the initial transcripts.

PART FOUR: Reliability Training

A training session will be conducted prior to the actual reliability testing, by the investigator, using the same procedures as outlined above. The training session will include practice identification of three different content transcripts. The reliability raters must be in 100 percent agreement with each other in order to start reliability testing, any differences will be discussed with all members of the reliability team until everyone is in agreement over the disfluency identification. 